\title{
Faktor Sosial Budaya yang Memengaruhi Kesehatan Ibu dan Anak (Studi Etnografi)
}

\author{
Social Cultural Factors Affecting the Health Of Mother and Child \\ (Ethnographic Study)
}

\author{
Salsabila $^{1}$, Zakiyatul Faizah ${ }^{2}$, Budi Prasetyo ${ }^{3}$ \\ Universitas Airlangga \\ 1Email: salsabila-2020@fk.unair.ac.id
}

\begin{abstract}
ABSTRAK
Kesehatan ibu dan anak sebagai indikator kunci kesejahteraan masyarakat diukur dengan Angka Kematian Ibu (AKI) dan Angka Kematian Bayi (AKB). Permasalahan kematian ibu dan anak merupakan masalah yang tidak bisa dipisahkan dengan kebudayaan atau perilaku masyarakat itu sendiri. Sistem sosial dan budaya di masyarakat merupakan sebuah pertimbangan penting dalam pelayanan kesehatan yang bisa dimanfaatkan lebih optimal. Tujuan penelitian ini adalah mengetahui faktor budaya apa saja yang memengaruhi kesehatan ibu dan anak. Penelitian ini adalah etnografi cepat atau rapid ethnographic assessment procedur (REAP) dengan pendekatan kualitatif. Tekhnik pengambilan sample menggunakan snowball atau chain referral sampling. Dilakukan secara berantai dari suatu partisipan kepada partisipan lainnya. Merupakan variasi dari sampel purposive. Jumlah responden sebanyak 8 orang yang sesuai dengan kriteria inklusi. Data yang ditunjukkan merupakan hasil wawancara mendalam (Indepth Interview) dan FGD (Focus Group Discussion). Penelitian ini menghasilkan temuan tentang : (1) Kiyai menjadi panutan masyarakat dalam menyikapi persoalan hidup mulai dari pilihan politik hingga pilihan akses kesehatan. (2) Perempuan tidak memiliki kuasa yang cukup penuh atau memberdayakan dirinya untuk memilih layanan kesehatan, terlebih dalam kondisi hamil dan melahirkan. (3) Unsur kepercayaan warisan turun temurun turut membentuk sistem pengetahuan masyarakat Cibitung. (4) Sistem mata pencaharian buruh tani sebagai sumber utama ekonomi di Cibitung.
\end{abstract}

Kata Kunci: Sosial Budaya, Etnografi, Sistem Religi, Sistem Kekerabatan, Sistem Pengetahuan, Sistem Mata Pencaharian

\begin{abstract}
Maternal and child health as a key indicator of community welfare is measured by Maternal Mortality Rate (MMR) and Infant Mortality Rate (IMR). The problem of maternal and child mortality is a problem that cannot be separated from the culture or behavior of the community itself. The social and cultural system in the community is an important consideration in health services that can be utilized more optimally. The purpose of this study was to determine what cultural factors affect the health of mothers and children. This research is a rapid ethnographic assessment procedure (REAP) with a qualitative approach. Sampling technique using snowball or chain referral sampling. It is carried out sequentially from one participant to another. Is a variation of the purposive sample. The number of respondents as many as 8 people who fit the inclusion criteria. The data shown were the result of indepth interviews and FGDs (Focus Group Discussion). This study resulted in findings about: (1) Kyai become community role models in responding to life's problems ranging from political choices to choices of access to health. (2) Women do not have sufficient full power or empower themselves to choose health services, especially during pregnancy and childbirth. (3) The element of belief inherited from generation to generation also forms the knowledge system of the Cibitung community. (4) The livelihood system of farm laborers as the main source of the economy in Cibitung.
\end{abstract}

Keywords: Socio-Cultural, Ethnographic, Religious Systems, Kinship Systems, Knowledge Systems, Livelihood Systems 


\section{PENDAHULUAN}

Angka Kematian Ibu (AKI) merupakan salah satu indikator dari upaya peningkatan kesehatan ibu. Budaya dan sistem sosial yang ada di masyarakat merupakan bagian yang menyumbang angka kematian ibu selain fasilitas dan pelayanan kesehatan. Selama ini intervensi dilakukan belum sepenuhnya mempertimbangkan faktor sosial budaya. (perempuan jurnal, 2019)

Berdasarkan data Dinas Kesehatan Kabupaten Bandung Barat, pada 2016 AKI berjumlah 40 kasus, sedangkan AKB berjumlah 116 kasus. Kebudayaan didefinisikan dengan berbagai cara. Menurut Spradley kebudayaan sebagai pengetahuan yang diperoleh, yang digunakan untuk menginterpretasikan pengalaman dan melahirkan tingkah laku sosial. (Spradley, 2016)

Kepekaan, persepsi masyarakat, mempertimbangkan kearifan lokal termasuk aturan dan keyakinan yang ada di masyarakat, sebagai faktor yang berpengaruh terhadap kinerja pelayanan kesehatan secara keseluruhan dan mempengaruhi seseorang dalam bertindak termasuk dalam upaya memanfaatkan pelayanan kesehatan. (Rahman, Sulthonie and Solihin, 2018)
Sebagai contoh, dalam budaya Sei, bayi yang baru lahir ditempatkan di dalam rumah yang di bawahnya diberi pengasapan telah menyebabkan tingginya angka kesakitan gangguan pernapasan pada bayi baru lahir. Dalam proses ini pendekatan budaya merupakan salah satu cara penting dan tidak bisa diabaikan. (perempuan jurnal, 2019)

Kesehatan ibu dan anak (KIA) merupakan upaya Kesehatan Ibu dan Anak di bidang kesehatan yang menyangkut pelayanan dan pemeliharaan ibu hamil, ibu bersalin, ibu meneteki, bayi dan anak balita serta anak prasekolah.(Prastyawati, 2011).

Salah satu tujuan program kia yaitu, Meningkatnya kemampuan dan peran serta masyarakat, keluarga dan seluruh anggotanya untuk mengatasi masalah kesehatan ibu, balita, anak prasekolah, terutama melalui peningkatan peran ibu dan keluarganya. (Nuraeni, 2011)

Strategi Program Kesehatan Ibu dan Anak (KIA) yaitu: advokasi, bina suasana, pemberdayaan masyarakat, dan kemitraan (Notoadmodjo, 2008).

Pada sistem religi kuatnya nilai agama yang ada dalam kebudayaan masyarakat, membuat sistem-sistem 
nilai dari kebudayaan tersebut terwujud sebagai simbol-simbol suci yang memiliki makna religious (Roland Robert, 1993. Emile Durkheim (1961). (Politika, 2020)

Adapun sistem kekerabatan adalah sebuah simbol yang terjadi dalam diri manusia. Kekerabatan mengandung arti yang sangat luas terkait bidang politik, ekonomi, pendidikan, kesehatan dan kehidupan sosial lainnya untuk keberlangsungan hidup manusia. (Mardotillah, 2015)

Sistem pengetahuan atau kognitif merupakan dominan yang sangat penting dalam membentuk tindakan seseorang (overt behavior). Dari pengetahuan dan penelitian ternyata prilaku yang didasari pengetahuan akan lebih langgeng dari pada prilaku yang tidak didasari oleh pengetahuan. (Notoatmojo, 2010)

Sistem mata pencaharian merupakan aktivitas manusia untuk memperoleh taraf hidup yang layak dimana antara daerah yang satu dengan daerah lainnya berbeda, sesuai dengan taraf kemampuan penduduk dan lingkungan tempat tinggalnya; secara tradisional penduduk biasanya akan memanfaatkan sumber alam disekitar mereka. (Koentjaraningrat., 1984)
Adapun tujuan penelitian ini yaitu untuk mengetahui faktor budaya apa saja yang mempengaruhi kesehatan ibu dan anak dari segi sistem religi, sistem kekerabatan, sistem pengetahuan, dan sistem mata pencaharian. (Angkasawati and Handayani, 2013)

\section{METODE PENELITIAN}

Jenis penelitian yang digunakan adalah rapid ethnographic assessment procedur (REAP) dengan pendekatan kualitatif yang dilakukan pada bulan Oktober 2021. Lokasi penelitian di Desa Cibitung Kecamatan Rongga Kabupaten Bandung Barat.

Tipe sampling di penelitian ini adalah teknik snowball atau chain referral sampling: Teknik ini disebut juga teknik pengumpulan data melalui informan terpilih dengan cara menanyakan kepada informan pihak yang dapat diwawancara berikutnya yang mengenal adat istiadat masyarakat setempat.

Instrument penelitian menggunakan alat perekam dan juga teks wawancara yang berisi 13 pertanyaan, diantaranya:

1. Bagaimana kebiasaan dalam keagamaan masyarakat cibitung? 
2. Bagaimana kebiasaan masyarakat yang berhubungan dengan keagamaan jika dari segi persoalan kehamilan atau melahirkan ?

3. Bagaimana jika dari segi kekerabatan/kekeluargaan dalam kondisi kehamilan atau melahirkan?

4. Bagaimana keterkaitannya ikatan kekeluargaan dengan keadaan paraji $?$

5. Ada kah kebiasaan lainnya dari masyarakat yang terkait dengan kelahiran?

6. Bagaimana pendidikan ataupun sistem pendidikan masyarakat cibitung?

7. Bagaimana pendapat orang tua mengenai pernikahan dini dan mengenai KB (Keluarga Berencana) ?

8. Bagaimana pendapat orang tua mengenai pernikahan dini dan mengenai KB (Keluarga Berencana) $?$

9. Di cibitung untuk mayoritas warganya bermata pencaharian apa?

Pengumpulan data primer dilakukan dengan diskusi kelompok terarah (focus group discussion/ FGD), wawancara mendalam (indepth interview), dan observasi. Jenis data yang dikumpulkan terdiri dari data primer dan data sekunder. Data sekunder diperoleh melalui studi kepustakaan, dokumen dari Dinas Kesehatan dan instansi terkait, maupun sumber-sumber lain yang sesuai dengan standar keilmiahan sumber data.

Adapun parameter faktor sosial budaya yang akan peneliti kaji, yaitu mengenai sistem religi, sistem kekerabatan, sistem pengetahuan, dan sistem mata pencaharuian.

Peneliti mengambil responden/informan sebanyak 8 orang yang terdiri dari 1 tokoh masyarakat, 1 tokoh agama, 1 bidan desa, 2 ketua RT, 2 ketua RW, dan 1 warga seorang ibu yang dilakukan pengambilan informasi secara wawancara mendalam (Indepth interview). Untuk FGD dan wawancara dilakukan oleh peneliti sendiri

Tekhnik analisis data yang digunakan yaitu reduksi data, transkrip data, penyajian data, pengkodean, kategorisasi, dan menarik kesimpulan

\section{HASIL DAN PEMBAHASAN}

Analisis menggunakan empat unsur budaya yaitu sistem kepercayaan/religi, sistem kekerabatan, sistem pengetahuan dan sistem mata pencaharian, terdapat beberapa faktor 
yang cukup dominan dalam mempengaruhi kesehatan ibu dan anak.

Sistem religi: keagamaan yang di dalamnya terdapat tokoh agama dan ulama sangat mendukung aktivitas pemerintah. Hal ini berdasarkan jawaban dari informan, seperti berikut:

"Tokoh agama ajengan ulama semua mendukung aktivitas pemerintah sangat membantu”.

Di Cibitung terdapat sejarah pemikiran dan peradaban KH. Ilyas (Mama Cibitung) yang peran dan pengaruhnya masih sangat mengakar serta berkembang sampai sekarang. Ratusan ribu santri yang tersebar di berbagai wilayah Jawa Barat sejak dahulu berhasil menjadikannya sebagai ulama yang disegani kiprah dan pemikirannya. Hal ini dilihat dari beberapa jawaban yang dilontarkan oleh beberapa informan sebagai berikut:

"Pan didieu mah aya pondok neng, pondok mama cibitung. Nami aslina mah Kh. Ilyas nya pak?"

(Bahasa sunda: "kan di sini mah ada pondok neng, pondok mama cibitung. Nama aslinya Kh. Ilyas")
"Eta mah bener-bener ti kapungkur pisan neng. Nya ai ayeuna mah tos ngantunkeun, tapi pan seeur muridmuridna nu ayeuna janten sesepuh didieu. Mun unggal aya ziarah oge eta mah neng dugi ka aya lah ribuan nya pak? Warga teh timana-mana"

(Bahasa sunda: " itu mah bener-bener dari dulu banget neng. Kalau sekarang mah sudah meninggal, tapi kan banyak murid-muridnya yang sekarang jadi sesepuh/ yang di tua-kan di sini. Kalau setiap ada ziarah juga itu mah neng dugi ka ada lah ribuan ya, pak? Warga teh dari mana-mana.”)

Dalam perkembangannya tentu tak jarang doktrin yang diterima oleh masyarakat menjadi sebuah paradigma dalam melihat perkembangan zaman. Secara keseluruhan, pesantren Mama Cibitung memainkan peran strategis dalam mengawal tumbuh kembangnya warga masyarakat dalam memegang teguh ajaran islam. Maka dalam konteks bermasyarakat, warga Cibitung relative religious nasionalis. Hal ini dilihat dari beberapa jawaban yang dilontarkan oleh beberapa informan sebagai berikut: 
Pokokna baheula mah religious lah urang teh ti nu awalna sok ngadu domba jadi henteu”

(Bahasa sunda: "pokoknya dulu mah religious lah kita teh dari yang awalnya suka meng-adukan domba jadi engga")

Dalam hal ini jika dikaitkan dengan persoalan keagamaan, masyarakat tidak memiliki larangan khusus dari segi kehamilan dan persalinan untuk tidak melahirkan di Bidan atau fasilitas kesehatan lainnya. Untuk saat ini bahkan persalinan sudah cukup maju dengan bersalin di Bidan. Akan tetapi, peran paraji tidak hilang sepenuhnya, melainkan masih membantu seperti merawat ibu yang hamil, memijit, dan membantu melahirkan sisa sepeti plasenta atau ariari. Walaupun sebagian masyarakat sudah paham bahwa dari segi hukum, melahirkan itu harus oleh bidan dan tidak boleh paraji. Hal ini dilihat dari beberapa jawaban yang dilontarkan oleh beberapa informan sebagai berikut:

"Secara spiritual kita tidak ada permasalahan, tidak ada eeuhh naon nya penghalang lah yang menghalangi buat kita teh "ah ulah lah ntong ngalahirkeun di bidan", hentu”.
(Bahasa sunda: secara spiritual kita tidak ada permasalahan, tidak ada penghalang lah yang menghalangi buat kita teh missal: "jangan lah, jangan melahirkan di bidan". Tidak ada".

"Hanya saja kita itu kadang berbenturan dengan yang namanya paraji nya kan "ai di kampong mah, paraji kan aya keneh dugi ka ayeuna". (Bahasa sunda: hanya saja kita itu kadang berbenturan dengan yang namanya paraji ya kan. Kalau di kampung mah di sini kan masih ada sampai sekarang”)

"Paraji boleh menolong tapi bukan menolong nya, hanya membantu, tetep ai nu menolong mah bidan nya, hanya saja paraji sebatas membantu "anu tos kaluarna sapertos bali na",

(Bahasa sunda: tapi di sini juga secara hukum mah tidak boleh, kita dari polsek apa-apa sudah ada kesepakatan. Paraji boleh menolong tapi bukan menolong nya, hanya membantu, tetep yang menolong mah bidan nya. Hanya saja paraji sebatas membantu yang sudah keluarnya sepeti plasenta atau ari-ari) yang sudah keluar seperti plasenta/ ariari) 
Sistem kekerabatan: Di cibitung dalam kasus ibu melahirkan, bagi warga yang rumahnya di pelosok, untuk mengakses pusat kesehatan, masyarakat bergotong royong membantu proses awal sampai akhir. Ada yang meminjamkan kendaraannya, bahkan tak sedikit saling membantu urusan perjalanan persalinan. Hal ini dilihat dari beberapa jawaban yang dilontarkan oleh beberapa informan sebagai berikut:

"ah neng di urang mah urusan eta sami wae pami saling bantos na mah teu hariwang. Dina aya nu ngalahirkeun oge wargi didieu mah balageur pisan” (Bahasa sunda: “ ah neng di kita mah urusan itu sama aja kalau saling bantu nya mah gak khawatir. Kalau ada yang melahirkan juga warga di sini mah pada baik sekali")

Dalam hal ini warisan turun temurun atau kepercayaan yang berupa pengalaman orang tua dan mertua dianggap dapat memengaruhi kegiatan persalinan oleh paraji. Sampai saat ini keberadaan paraji masih ada. Ada yang bermitra dengan baik, ada juga yang masih kekeuh dan keberadaan serta praktiknya bersifat sembunyi-sembunyi. Padahal di cibitung, masyarakat sudah bekerja sama dengan pihak keamanan seperti polsek dan koramil untuk menertibkan paraji tersebut. Hal ini dilihat dari beberapa jawaban yang dilontarkan oleh beberapa informan sebagai berikut:

" tingkat pendidikan kita itu mah sangat berpengaruh nya, kacontoan kieu ayeuna mah duduluran, mereunan si paraji eta pan wargina nu bade ngalahirkeun kekeuh, terus dari awal "da mamah ge baheula ku si euma eta masih lahiranna, da teu nanaon aman". (Bahasa sunda: " tingkat pendidikan kita itu mah sangat berpengaruh ya. Contohnya persaudaraan, mungkin si paraji kan saudaranya yang akan melahirkan, dan kekeuh terus dari awal kalau "mamah juga dulu lahirnya sama si mak paraji, tidak apa-apa aman"

“Tapi tetep paraji masih ada, ada yang bermitra baik, aya oge anu susulumputan. Padahal kita sudah bermitra dengan keamanan seperti polsek sama koramil untuk menertibkan mak mak paraji meh teu jadi lalakonna. (Bahasa sunda: “ tapi tetep paraji masih ada, ada yang bermitra baik, ada juga yang sembunyi-sembunyi. Padahal kita sudah bermitra dengan keamanan 
seperti polsek sama koramil untuk menertibkan mak mak paraji supaya tidak jadi dalangnya/pemimpinnya.")

Dahulu di cibitung bidan itu hanya menangani sisa-sisa dari yang telah dilakukan oleh paraji. Dalam satu kasus yang memerlukan rujukan ke rumah sakit oleh bidan, menjadikan masyarakat lebih memilih persalinan di paraji yang tidak pernah melakukan rujukan ke rumah sakit. Yang mendasari hal ini yaitu, jika bidan merujuk persalinan ke rumah sakit, menurut masyarakat itu artinya bahwa bidan dianggap tidak mampu dalam menangani persalinan.

"Bahkan biasana bidan itu menangani sisa sisa dari paraji, mun geus parah kakara, kadang aya anu ceuk bidan kudu dirujuk da moal bisa ditangani ku urang, pindah ka paraji ngalahirkeunna, akhirna kan masyrakat wah gening ku paraji teu kudu dirujuk kitu kan, leuwih bisa paraji”.

(Bahasa sunda: “ bahkan biasanya bidan itu menangani sisa-sisa dari paraji, kalau sudah parah baru (dialihkan ke bidan). Kadang ada yang kata bidan harus dirujuk karena tidak bisa ditangani oleh bidan, masyarakat pindah ke paraji melahirkannya. Akhirnya kan masyarakat merasa "ah ternyata lahir sama paraji tidak perlu dirujuk (*ke rumah sakit) seperti itu kan(?) lebih bisa paraji” )

Penelitian serupa pernah dilakukan oleh Aryastami terjadi di Suku Aceh Barat dalam tradisinya melahirkan ditolong oleh 'baliem' karena faktor budaya dan keputusan keluarga; demikian juga pada suku Oyog di Cirebon, memilih bersalin dengan dukun karena secara emosional merasa lebih dekat. Sedangkan di Suku Laut (Kabupaten Inderagiri Hilir) dan suku Buru (Kabupaten Buru), pemilihan dukun sebagai penolong persalinan lebih disebabkan karena faskes yang sulit dijangkau(Aryastami and Mubasyiroh, 2019)

Sistem pengetahuan: rata-rata masyarakat cibitung menempuh pendidikan terakhir sampai kelas 1 SMP. Faktor utamanya adalah ekonomi dan mindset masyarakat bahwa pendidikan tak ada apa-apanya jika hanya tinggal di kampung saja. Tapi saat ini sudah mulai bermunculan sekolah SMP dan SMA. Ketika sudah lulus SMP, biasanya masyarakat di desa 
cibitung melakukan pernikahan, atau biasa disebut pernikahan dini.

"kalo di rata-ratakan semua jumlah yang berpendidikan di sini nyaeta hanya kelas 1 smp".

(Bahasa sunda : "kalau di rata-ratakan semua jumlah yang berpendidikan di sini yaitu hanya kelas $1 \mathrm{smp")}$

"da sebenerna ayeuna pan asa percuma mun sakola luhur-luhur tapi cicing didie panan kumaha nya? teu aya hasilna kitu”

(Bahasa sunda : " sebenarnya sekarang seperti percuma kalau sekolah tinggitinggi tapi diem di sini saja kan gimana ya? Tidak ada hasilnya gitu”)

"Di urang masih banyak pernikahan dini yang beres smp, tapi seks bebas jarang atau bisa disebut teu aya".

(Bahasa sunda : "Di kita masih banyak pernikahan dini yang beres SMP, tapi seks bebas jarang atau bisa disebut tidak ada")

Pernikahan dini menjadi pilihan bagi orang tua terhadap anaknya. Menurut masyarakat di cibitung tidak terdapat kasus seks bebas yang dilakukan oleh remaja. Hal yang mendasarinya yaitu pandangan orang tua bahwa "lebih baik dinikahkan segera daripada hamil di luar pernikahan". Menurut warga, bahwa hamil di luar pernikahan membuat malu orang tua.

"Jadi didie mah kolotna kumaha carana meh teu seks bebas jadi buruburu dikawinkeun solusina. Masyarakat di urang daripada hamil tiheula, mending dikawinkeun".

(Bahasa sunda : “ jadi di sini mah orang tua nya gimana caranya supaya tidak seks bebas jadi cepat-cepat dinikahkan solusinya. Masyarakat di kita daripada hamil duluan, mending dinikahkan")

Adapun data statistik menunjukkan bahwa pernikahan di bawah umur tercatat di Dinas Pengendalian Penduduk Keluarga Berencana Pemberdayaan Perempuan dan Perlindungan Anak (DPPKBP3A) bahwa angka pernikahan dini di Kabupaten Bandung Barat masih tinggi. Pada tahun 2017 menunjukan bahwa usia di bawah atau sama dengan dari 20 tahun untuk umur istri yang paling banyak presentase nya di Kecamatan Rongga dengan angka $90.44 \%$, sedangkan untuk suami dengan angka 
cukup tinggi yakni $74.68 \%$. Kecamatan

Rongga merupakan salah satu kecamatan di Kabupaten Bandung Barat yang memiliki angka perkawinan di usia di bawah 20 tahun untuk perempuan yang masih tinggi yakni pada tahun 2015 sebanyak 87,66 \%, tahun $201691,80 \%$ dan tahun 2017 sebanyak 90,44\%.(Attia, 1974)

Pada sebuah penelitian yang dilakukan oleh Ni Ketut Aryastami dan Rofingatul Mubasyiroh pada November 2019 juga mengatakan bahwa terdapat hubungan antara perkawinan usia dini dengan tingkat pendidikan yang rendah, tidak sekolah dan tidak tamat SD $(43,1 \%)$, termasuk dalam kategori keluarga miskin $(46,2 \%)$ dan tinggal di perdesaan (48,7\%). (Aryastami and Mubasyiroh, 2019)

Adapun saat ini juga pengetahuan warga mengenai $\mathrm{KB}$ (Keluarga Bencana) sudah cukup baik. Dahulu satu keluarga bisa memiliki 8,9, dan sampai 10 anak. Menurut warga, Cibitung dan Sukamanah merupakan desa yang tingkat reproduksinya paling tinggi di kecamatan Rongga. Kondisi ini terakhir berlangsung pada tahun 2005. Sekarang paling banyak pun hanya 2-3 anak. Untuk saat ini di cibitung jika sehabis menikah, biasanya menunda kehamilan terlebih dahulu.

"Sekarang di cibitung dulu yang punya anak minimal harus 8-9 anak, tapi ayeuna mah engga".

(Bahasa sunda : "Sekarang di cibitung dulu yang punya anak minimal harus 89 anak tapi sekarang mah engga")

"Alhamdulillah KB sudah mulai berjalan jadi nya lain nutup rejeki jadi KB insyaallah sudah baik di kita 2-3 anak".

(Bahasa sunda : "Alhamdulillah KB sudah mulai berjalan jadi ya bukan nutup rejeki jadi $\mathrm{KB}$ insyaallah sudah baik di kita 2-3 anak")

"Kadang ayeuna mah awal nikah kan nunda dulu. Terakhir sekitar tahun 2005 nu masih boga budak ngaberebet" (Bahasa sunda : "Kadang sekarang mah awal nikah kan nunda dulu. Terakhir sekitar tahun 2005 yang masih punya anak berturut-turut banyak")

"Desa cibitung dan sukamanah nu paling parah boga budak na teh 10”.

(Bahasa sunda : "Desa cibitung dan sukamanah yang paling parah punya anaknya sampai 10.”) 
Sistem mata pencaharian: Desa Cibitung memiliki mata pencaharian sebagai buruh tani yang menggarap ladang sawah milik warga sekitar. Komoditas unggulannya adalah selain beras yaitu gula aren (kawung). Dahulu, Desa Cibitung merupakan desa pemasok TKW \& TKI ke Saudi Arabia.

"Di kita mah orang sini jadi buruh tani, ai petani na mah bos bos na we biasa ngan angger orang dieu keneh".

(Bahasa sunda : "Di kita mah orang sini jadi buruh tani, kalau petani nya mah bos bos nya aja biasa Cuma tetap masih orang sini.")

"Beas jeung gula bereum untuk penghasilan tambahan rata rata diperjual belikan ke pengepul nu orang jauh”.

(Bahasa sunda : "Beras dan gula merah untuk penghasilan tambahan rata rata diperjual belikan ke pengepul yang orang jauh")

"Dulu mah cibitung teh basis TKW mangkana banyak rumah rumah besar tuh punya arab.

(Bahasa sunda : " dulu mah cibitung teh basis TKW mangkanya banyak rumah-rumah besar tuh punya arab.

\section{SIMPULAN DAN SARAN}

Berdasarkan seluruh hasil tahapan penelitian yang telah dilakukan dalam mengkaji faktor sosial budaya yang memengaruhi kesehatan ibu dan anak di kecamatan rongga kabupaten bandung barat dapat disimpulkan sebagai berikut:

$$
\text { Kyai menjadi panutan }
$$

masyarakat dalam menyikapi persoalan hidup mulai dari pilihan politik hingga pilihan akses kesehatan.

Keputusan dalam menentukan layanan kesehatan atau perawatan untuk ibu hamil dan melahirkan (contoh: melahirkan di dukun/paraji) dilakukan oleh ibu kandung atau ibu mertua, yang menjadikan perempuan tidak berdaya.

Nilai yang diwariskan erat kaitannya dengan pengalamanpengalaman orang tua dahulu. Nilai ini memengaruhi pengetahuan tentang konsep memiliki anak atau reproduksi.

Sistem mata pencaharian buruh tani sebagai sumber utama ekonomi di cibitung.

Adapun saran dari penelitian ini yaitu: Perlu pembekalan metode antropologi kesehatan yang mudah diterapkan secara berjenjang bagi tenaga kesehatan di Puskesmas, RS, 
Dinas Kesehatan, dan Kementerian Kesehatan.

Mengembalikan fungsi dasar Puskesmas sebagai unit pelayanan yang berbasis kewilayahan bukan hanya teritori secara geografis namun juga teritori secara sosial budaya.

Pemerintah dalam membuat kebijakan perlu mempertimbangkan faktor budaya dan struktur sosial.

Kampanye kesehatan di Cibitung melalui pondok pesantren dan meminta kyai menjadi juru kampanye kesehatan.

Lebih menguatkan pendekatan terhadap paraji agar dapat bermitra secara baik dengan bidan dan juga lingkungan setempat.

\section{DAFTAR PUSTAKA}

Angkasawati, T. J. and Handayani, L. (2013) Simpang Jalan Pelayanan Kesehatan Ibu \& Anak: Sebuah Studi Etnografi. Available at: www.kanisiusmedia.com.

Aryastami, N. K. and Mubasyiroh, R. (2019) 'Peran Budaya dalam Pemanfaatan Layanan Kesehatan Ibu Hamil', (November), pp. 1-7.
Attia
(1974)
'No
Title专业外语有屁用, 信阳师范学院, 10(2), pp. 1-15.

Koentjaraningrat. (1984) 'Kebudayaan, Mentalitas dan Pembangunan.'

Mardotillah, M. (2015) 'Perspektif Antropologi Kesehatan; Peran Kekerabatan Dalam Keberhasilan Asi Ekslusif Di Kota Bandung'.

Notoadmodjo, S. (2008) 'Kesehatan Ibu dan Anak.' Jakarta: Rineka Cipta.

Notoatmojo, S. (2010) 'Ilmu Perilaku Kesehatan.'

Nuraeni, A. (2011) 'Sistem Informasi Pelayanan Kesehatan Ibu dan Bayi di PUSKESMAS', Pkko.Fik.Ui.Ac.Id. Available at: http://pkko.fik.ui.ac.id/files/uts sim asti.pdf.

Perempuan jurnal (2019) 'No Title', pengumpulan data untuk memenuhi target SDGs, 102, p. 28.

Politika, J. T. (2020) 'Sistem Religi Sebagai Identitas Sosial Budaya Masyarakat Sumatera Selatan Dalam Perspektif Sosiologis Dendi Sutarto', 4(1), pp. 75-89.

Prastyawati, A. E. (2011) 'Nuha Medika', Ilmu Kesehatan Masyarakat untuk Kebidanan Holistik.

Rahman, M. T., Sulthonie, A. A. and Solihin, S. (2018) "'Sosiologi Informasi Pengobatan Tradisional Religius" Kajian di Masyarakat Perdesaan Jawa Barat', Jurnal Studi Agama dan Masyarakat, 14(2), p. 100. doi: 10.23971/jsam.v14i2.724. 
Spradley, J. p (2016) The Ethnographic

Interview. Florida: Waveland

Press. 